\title{
A framework for assessing risk to coastal ecosystems in Taiwan due to climate change
}

\author{
Ming-Chih Chiu ${ }^{1,2}$, Ching-Wen Pan ${ }^{2}$, and Hsing-Juh Lin ${ }^{2,3, *}$ \\ ${ }^{1}$ Department of Environmental Science, Policy \& Management, University of California at Berkeley, Berkeley, CA, U.S.A. \\ ${ }^{2}$ Department of Life Sciences and Research Center for Global Change Biology, National Chung Hsing University, Taichung City, \\ Taiwan \\ ${ }^{3}$ Biodiversity Research Center, Academia Sinica, Taipei City, Taiwan
}

\section{Article history:}

Received 18 November 2015

Revised 23 May 2016

Accepted 30 June 2016

Keywords:

Acidification, Exposure, Hazard, Sea level rise, Warming, Vulnerability

Citation:

Chiu, M. C., C. W. Pan, and H. J. Lin, 2017: A framework for assessing risk to coastal ecosystems in Taiwan due to climate change. Terr. Atmos. Ocean. Sci., 28, 57-66, doi: 10.3319/ TAO.2016.06.30.01(CCA)

\begin{abstract}
Coastal ecosystems are rich with biodiversity and ecological functions that provide valuable ecosystem services. They are also vulnerable to the impacts of climate change and anthropogenic activities. Assessing the impacts of climate change on coastal ecosystems is crucial if we are to develop and implement strategies that minimize and mitigate these impacts. This study uses a theoretical framework that includes climatic hazards, ecosystem vulnerability, and exposure to damaging climatic events, to estimate the risks due to climate change on coastal ecosystems in Taiwan. We found that seagrass beds, algal reefs, and coral reefs in Taiwan are at high ecological risk to the future effects of sea level rise, elevated sea temperature, and ocean acidification. The responses of these highly threatened ecosystems to the effects of climate change is uncertain and depend, in part, on the type of ecosystem, its location in Taiwan, the rate at which these effects occur, and whether these impacts occur at the same time or sequentially. The coastal ecosystem risk to the adverse effects of climate change is high because they are especially vulnerable. The resistance of coastal ecosystems is linked to their complexity and maturity. Their low adaptive capacity is linked to the exploitation of their natural resources and inadequate biodiversity conservation. To minimize and mitigate the effects of climate change on high-risk areas and ecosystems ongoing monitoring programs and dynamic management will be needed. Our study is a first step toward building a framework for climate change risk assessment for the coastal ecosystems in Taiwan.
\end{abstract}

\section{INTRODUCTION}

Increased greenhouse gas atmospheric concentrations are causing climate change. Ecosystems have already suffered from the effects of climate change, especially in many coastal areas (Gillanders et al. 2011). Climate change, including an increase in global temperatures and the frequency of extreme weather events, is predicted to be lasting and pose risks to environmental features and biotic assemblages in terrestrial and aquatic ecosystems (IPCC 2013). For coastal ecosystems, ocean warming, ocean acidification, and sea level rise are the three most important changes caused by climate change. There is a growing awareness of the consequences of increasing atmospheric $\mathrm{CO}_{2}$, which could in-

\footnotetext{
* Corresponding author

E-mail:hjlin@dragon.nchu.edu.tw
}

crease ocean temperatures and reduce seawater $\mathrm{pH}$ to levels intolerable to coastal ecosystems (Orr et al. 2005; Ateweberhan et al. 2013). In recent decades, overwhelming scientific findings about sea level rise and its impacts on low-lying coastal areas have gained the attention of coastal ecosystem managers around the world (Torresan et al. 2012; Li et al. 2015). Of particular concern is how ocean warming, ocean acidification, and sea level rise will interact with local socioeconomic development, such as land use, shoreline alterations, pollution, urbanization, and overfishing, and how these impacts can be mitigated. Each of these changes in the ocean and their interactions are contributing to notable impacts on global biodiversity and ecological functioning (McClanahan et al. 2012). Although these changes in the ocean are occurring now, the rate of change and the spatial and 
temporal variability in these three factors, and the ecosystem responses pose considerable uncertainty (Simas et al. 2001). Climate change presents a major challenge for ecological risk assessment (Yemshanov et al. 2013).

The marine-terrestrial interface that occurs in coastal areas includes a variety of unique ecosystems. Globally, management agencies have focused on the most threatened and heavily used coastal ecosystems, including marshes, mangroves, coral reefs, algal reefs, seagrass beds, sand beaches, and dunes (Halpern et al. 2008). These ecosystems are some of the most valuable ecosystems, due to their rich biodiversity, ecological functions and ecosystem services (Barbier et al.2011). Coastal ecosystems are among the most vulnerable to the impacts of climate change (Spalding et al. 2014). The rapid and increasing deterioration of coastal ecosystems due to human activities increases their vulnerability to climate change because it decreases their adaptive capacity (Czúcz et al. 2011). For example, coastal wetlands, reefs, and submerged vegetation can provide floodplains and erosion control against increasing coastal flooding events due to sea level rise and extreme storms, but human degradation of these ecosystems decreases coastal protection (Danielsen et al. 2005). Coastal ecosystems degraded by both human impact and future climatic events could suffer an accelerating loss of populations and species. This biodiversity loss could affect ecosystem services (Worm et al. 2006; Barbier et al. 2011). Coastal ecosystems provide fisheries, whose diminishment is cause for concern due to the paramount issue of food security worldwide (Ateweberhan et al. 2013). Oyster reefs, seagrass beds, and wetlands provide nursery habitats for fish and other organisms. Suspension feeders, submerged vegetation, and wetlands provide filtering and detoxification services (Worm et al. 2006). Degradation of these ecosystems decreases their stability and their capacity to maintain water quality by reducing their ability to recover from perturbations (Worm et al. 2006). Concern about ecosystem collapse associated with climate change has been a major factor contributing to the increase in coastal ecosystem risk assessment and impact mitigation.

Adaptation and mitigation strategies are developed based on the global climate change threats predicted on ecosystems (Chin et al. 2010). Risk assessment and its role in aiding the development of adaptive strategies to climate change have received increasing scientific and public attention (Anthony et al. 2015; Rogers et al. 2015). It is crucial that we develop methods for accurately analyzing the risk of climate change to coastal ecosystems. For ecological risk assessments, the hazard, vulnerability, and exposure are estimated and the risk is calculated based on the interaction of these three factors (IPCC 2014). Risk is defined as the product of the impacts from hazardous events and the probability that each event occurs. The impact of a hazardous event is affected by ecosystem vulnerability and exposure. Specifically, (1) the hazard is a latent damaging event for compo- nents of an ecosystem (e.g., biodiversity, ecological function, and ecosystem service); (2) vulnerability is determined by the sensitivity (lack of resistance) and adaptive capacity (degree of resilience) to the hazard; (3) exposure indicates the presence of the ecosystem components in spaces that could be adversely affected by the hazard. Both numerical modeling and index-based risk assessments have been conducted for a wide range of coastal systems (Chin et al. 2010; Hinkel et al. 2010). Based on a limited number of datasets, index-based methods are better able to include comprehensive, multidisciplinary information in ecological risk assessments for different regions and at large spatial scales. Unlike complex numerical models, their easy implementation can provide rapid assessments for urgent situations.

We used this theoretical framework and index-based method to estimate the risk of climate change to coastal ecosystems in Taiwan. We combined climatic hazard, ecosystem vulnerability (both sensitivity and adaptive capacity), and exposure to estimate the risk imposed by increases in ocean temperature, acidity, and sea level. Regional scale qualitative and quantitative attributes were used as environmental, ecosystem, and socioeconomic indicators of each risk factor. The socioeconomic indicators attempt to account for the exploitation of natural resources and the positive role of biodiversity conservation policies, which contribute to ecosystem resilience to climatic hazards. This assessment framework was developed to estimate the relative risk of climate change on coastal ecosystems in regional/subnational areas of Taiwan. Special attention was given to areas identified as having high ecological risk and to creating strategies that will enable these areas to avoid, mitigate, or adapt to these hazards.

\section{MATERIALS AND METHODS}

We followed the IPCC definitions of vulnerability, exposure and hazard to develop potential risk indicators and developed our framework (Fig. 1). We estimated relative risk based on observed (1980 - 1999) and projected (2020 - 2039) conditions. For each spatial patch on the Taiwan coast (Fig. 2), we calculated the risk from climate change as follows:

Risk $=\mathrm{V} \times \underbrace{\frac{\sum \mathrm{H}_{i} \times \mathrm{E}_{i}}{\mathrm{~N}}}_{\mathrm{HE}}$

where $\mathrm{V}$ is vulnerability (the average of sensitivity and the inverse of adaptive capacity), $\mathrm{H}_{i}$ is the hazard magnitude $i$, $\mathrm{E}_{i}$ is the ecosystem proportion exposed to hazard $i$, and $\mathrm{N}$ is the number of hazards. HE is the product of hazard and exposure.

We assumed the vulnerability of each ecosystem remained constant throughout the time period covered by this 
study. However, different ecosystems, such as coral reefs, mangroves, and algal reefs, may differ in their vulnerability to hazards. Exposure is an ecosystem- and hazard-specific variable. The ocean hazard magnitude on the Taiwan coast is based on the projection average for different general circulation models (GCMs). Hazard magnitude, ecosystem exposure, and each ecosystem vulnerability component were given a score (from 1 to 5) based on the criteria in Table 1.

We selected 9 sites on the Taiwan coast for which adequate ecological and socioeconomic information exists (Table 2). The vulnerability of each of the 7 types of coastal ecosystems was determined using one or two sites representative of each ecosystem. We excluded salt marshes from this study because there is inadequate data for this ecosystem in Taiwan. Societal impacts and protective legislation were also scored on a scale of 1 to 5 , so these factors can be included in the analyses.

Sensitivity, including Finn's cycling index, total bio- mass of consumers, total biomass/total production, total primary production/total respiration, system omnivory index, and overhead/development capacity, were determined using a trophic model of each site constructed using the Ecopath with Ecosim software (Christensen et al. 2008), which can characterize energy flows within the food web (Odum 1969; Ulanowicz 2001). We followed the general methodology to verify the Ecopath model realism (Christensen et al. 2008). The inverse of adaptive capacity determines ecological recovery potential and it is affected by the interaction of an ecosystem with socio-economic factors, including landscape development intensity (LDI) index (Chen and Lin 2011), the number of visitors, overfishing, and protective legislation. The effects of pollution could be associated with the number of visitors and LDI index.

We used an ensemble of four GCMs, i.e., GFDLESM2M, IPSL-CM5A-LR, NorESM1-ME, and GFDL-ESM2G. GCM runs for the four emission scenarios used in the

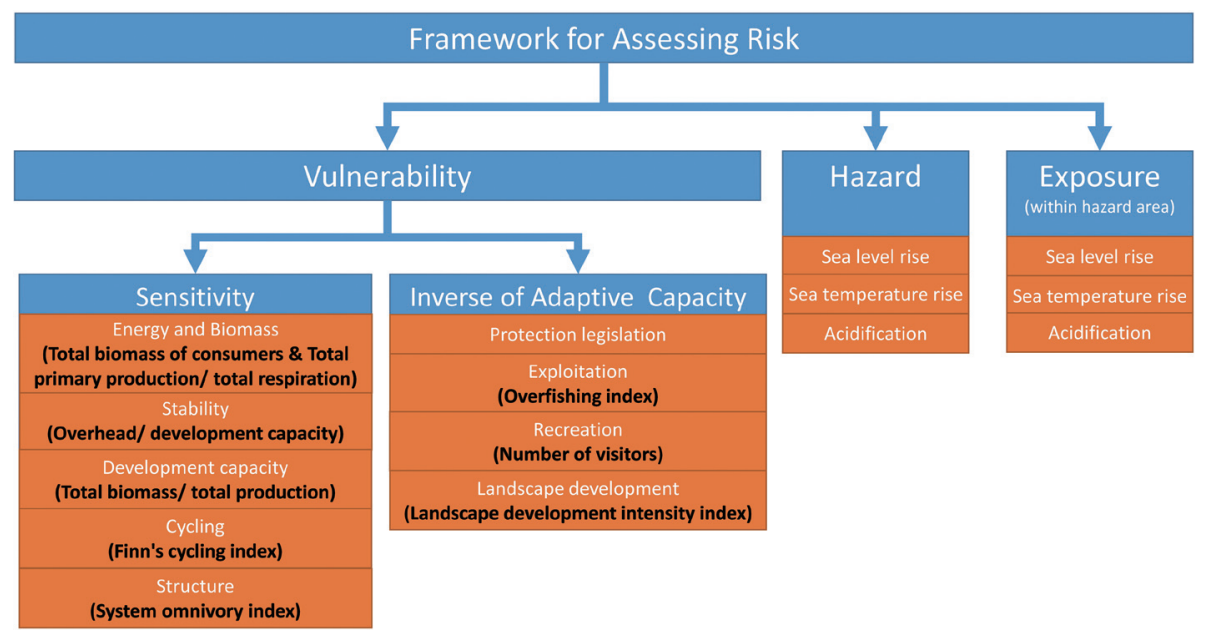

Fig. 1. Conceptual framework for assessing the climate change effects on coastal ecosystems. (Color online only)

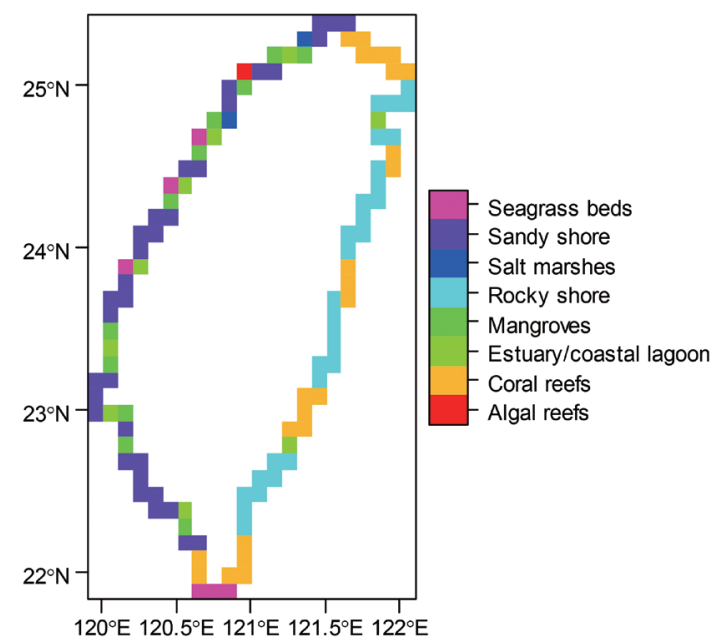

Fig. 2. Coastal ecosystem distribution in Taiwan. 
Table 1. Criteria for ranking hazard magnitude and ecosystem vulnerability and ecosystem exposure to three ocean hazards.

\begin{tabular}{|c|c|c|c|c|c|}
\hline \multirow{2}{*}{ Risk Factor } & \multicolumn{5}{|c|}{ Score } \\
\hline & 1 & 2 & 3 & 4 & 5 \\
\hline \multicolumn{6}{|l|}{ Vulnerability } \\
\hline \multicolumn{6}{|l|}{ Sensitivity } \\
\hline Finn's cycling index & High & Fairly high & Medium & Fairly low & Low \\
\hline Total biomass of consumers & High & Fairly high & Medium & Fairly low & Low \\
\hline Total biomass/total production & High & Fairly high & Medium & Fairly low & Low \\
\hline Total primary production/total respiration $\approx 1$ & High & Fairly high & Medium & Fairly low & Low \\
\hline System omnivory index & High & Fairly high & Medium & Fairly low & Low \\
\hline Overhead/development capacity & High & Fairly high & Medium & Fairly low & Low \\
\hline \multicolumn{6}{|l|}{ Inverse of adaptive capacity } \\
\hline Landscape development intensity index & Low & Fairly low & Medium & Fairly high & High \\
\hline Number of visitors & Low & Fairly low & Medium & Fairly high & High \\
\hline Overfishing index & Low & Fairly low & Medium & Fairly high & High \\
\hline Protection legislation & National area & $\mathrm{n} / \mathrm{a}$ & Regional area & $\mathrm{n} / \mathrm{a}$ & None \\
\hline \multicolumn{6}{|l|}{ Hazard } \\
\hline Sea level rise $(\mathrm{cm})$ & $<12.5$ & $12.5-25.0$ & $25.0-37.5$ & $37.5-50.0$ & $\geq 50.0$ \\
\hline Surface seawater temperature rise $\left({ }^{\circ} \mathrm{C}\right)$ & $<0.3$ & $0.3-0.6$ & $0.6-0.9$ & $0.9-1.2$ & $\geq 1.2$ \\
\hline Surface ocean $\mathrm{pH}$ decline & $<0.05$ & $0.05-0.10$ & $0.10-0.15$ & $0.15-0.20$ & $\geq 0.20$ \\
\hline Exposure (to each hazard) & Low & Fairly low & Medium & Fairly high & High \\
\hline
\end{tabular}

Table 2. Ecosystem vulnerability and exposure to ocean hazards. Scores were generated using the criteria shown in Table 1.

\begin{tabular}{|c|c|c|c|c|c|c|c|c|c|}
\hline & $\begin{array}{c}\text { Site } 1 \\
\text { Yenliao Bay } \\
\text { (Ye 2007) }\end{array}$ & $\begin{array}{c}\text { Site } 2 \\
\text { Datan (Lin } \\
\text { et al. 2013) }\end{array}$ & $\begin{array}{c}\text { Site } 3 \\
\text { Kenting } \\
\text { Nanwan } \\
\text { Bay (Liu et } \\
\text { al. 2009) }\end{array}$ & $\begin{array}{c}\text { Site } 4 \\
\text { Guandu } \\
\text { (Lin et al. } \\
\text { 2003) }\end{array}$ & $\begin{array}{c}\text { Site } 5 \\
\text { Dongsha } \\
\text { (Lee et al. } \\
\text { 2015) }\end{array}$ & $\begin{array}{c}\text { Site } 6 \\
\text { Chiku La- } \\
\text { goon (Lin et } \\
\text { al. 1999) }\end{array}$ & $\begin{array}{c}\text { Site } 7 \\
\text { Tapong Bay } \\
\text { (Lin et al. } \\
\text { 2006) }\end{array}$ & $\begin{array}{c}\text { Site } 8 \\
\text { The Estuary } \\
\text { of Xin Hu- } \\
\text { wei River } \\
\text { (Pan et al. } \\
\text { 2016) }\end{array}$ & $\begin{array}{c}\text { Site } 9 \\
\text { Kuosheng } \\
\text { Bay (Lin et } \\
\text { al. 2004) }\end{array}$ \\
\hline Ecosystem type & rocky shore & algal reefs & coral reefs & mangroves & $\begin{array}{l}\text { seagrass } \\
\text { beds }\end{array}$ & $\begin{array}{l}\text { estuary/ } \\
\text { coastal } \\
\text { lagoon }\end{array}$ & $\begin{array}{c}\text { estuary/ } \\
\text { coastal } \\
\text { lagoon }\end{array}$ & sandy shore & sandy shore \\
\hline GPS coordinate & $\begin{array}{l}121.87^{\circ} \mathrm{E}, \\
25.08^{\circ} \mathrm{N}\end{array}$ & $\begin{array}{l}121.08^{\circ} \mathrm{E}, \\
25.03^{\circ} \mathrm{N}\end{array}$ & $\begin{array}{l}120.77^{\circ} \mathrm{E}, \\
21.96^{\circ} \mathrm{N}\end{array}$ & $\begin{array}{l}121.42^{\circ} \mathrm{E}, \\
25.17^{\circ} \mathrm{N}\end{array}$ & $\begin{array}{c}116.92^{\circ} \mathrm{E}, \\
20.67^{\circ} \mathrm{N}\end{array}$ & $\begin{array}{l}120.08^{\circ} \mathrm{E} . \\
23.12^{\circ} \mathrm{N}\end{array}$ & $\begin{array}{l}120.46^{\circ} \mathrm{E}, \\
22.45^{\circ} \mathrm{N}\end{array}$ & $\begin{array}{c}120.20^{\circ} \mathrm{E}, \\
23.75^{\circ} \mathrm{N}\end{array}$ & $\begin{array}{l}121.67^{\circ} \mathrm{E}, \\
25.19^{\circ} \mathrm{N}\end{array}$ \\
\hline \multicolumn{10}{|l|}{ Vulnerability } \\
\hline Sensitivity & 2.00 & 4.50 & 2.50 & 4.00 & 3.83 & 2.17 & 2.50 & 3.67 & 2.17 \\
\hline $\begin{array}{l}\text { Inverse of adap- } \\
\text { tive capacity }\end{array}$ & 3.00 & 3.00 & 3.25 & 2.00 & 2.25 & 3.50 & 3.50 & 3.25 & 3.25 \\
\hline \multicolumn{10}{|l|}{ Hazard } \\
\hline Sea level rise & 1 & 1 & 1 & 1 & 1 & 1 & 1 & 1 & 1 \\
\hline $\begin{array}{l}\text { Surface seawater } \\
\text { warming }\end{array}$ & 3 & 3 & 3 & 3 & 3 & 3 & 3 & 3 & 3 \\
\hline $\begin{array}{l}\text { Surface ocean } \mathrm{pH} \\
\text { decline }\end{array}$ & 2 & 2 & 2 & 2 & 2 & 2 & 2 & 2 & 2 \\
\hline \multicolumn{10}{|l|}{ Exposure } \\
\hline Sea level rise & 2 & 1 & 2 & 4 & 4 & 4 & 4 & 1 & 1 \\
\hline $\begin{array}{l}\text { Surface seawater } \\
\text { warming }\end{array}$ & 1 & 4 & 5 & 2 & 3 & 3 & 3 & 1 & 1 \\
\hline $\begin{array}{l}\text { Surface ocean } \mathrm{pH} \\
\text { decline }\end{array}$ & 3 & 5 & 5 & 2 & 3 & 1 & 1 & 2 & 2 \\
\hline
\end{tabular}


IPCC Fifth Assessment Report (AR5; IPCC 2013) represent different greenhouse gas emissions (RCP26, 45, 60, and 80). We selected these GCMs because they have the four greenhouse gas emissions and four focal climatic hazards (Sea Surface Height above Geoid, Sea Surface Temperature, and Sea Water $\mathrm{pH}$ ). The 16 GCM-emission scenario combinations form a range of projections.

\section{RESULTS}

By 2039, the sea level is predicted to rise $3.1-3.5 \mathrm{~cm}$ all around Taiwan (Fig. 3) and will likely have similar effects on all coastal ecosystems (hazard score 1 , Table 2). Ocean surface temperature is expected to increase $0.66-0.73^{\circ} \mathrm{C}$, while the $\mathrm{pH}$ of coastal water will decrease $0.05-0.07$ (Fig. 3). The effects of increasing water temperature will likely be similar on the different coastal ecosystems and be greater (score 3 ) than the sea level rise effects (Table 2).
Likewise, the decrease in $\mathrm{pH}$ is expected to be similar in all coastal ecosystems (Fig. 3) and have a somewhat greater impact (score 2) than the sea level rise (Table 2). As a result, much of the variation in ecological risk posed by these hazards to the 7 types of coastal ecosystems (Table 3 ) is due to differences in the composite ecological vulnerability index and exposure to the hazards (Table 2). Due to high vulnerability and exposure, especially to increases in ocean temperature and acidity, the coastal ecosystems at the highest risk to the climate change effects include coral reefs, seagrass beds, and algal reefs (Table 3 ). Although coral reefs are not especially vulnerable to these hazards, they are still at high risk due to anthropogenic disturbance and high exposure to ocean warming and acidification. Seagrass beds suffer less from anthropogenic disturbance, but are still at high risk due to medium-high exposure and medium-high sensitivity to climatic hazards. Algal reefs are at the highest risk due to high vulnerability and high exposure to ocean hazards. This
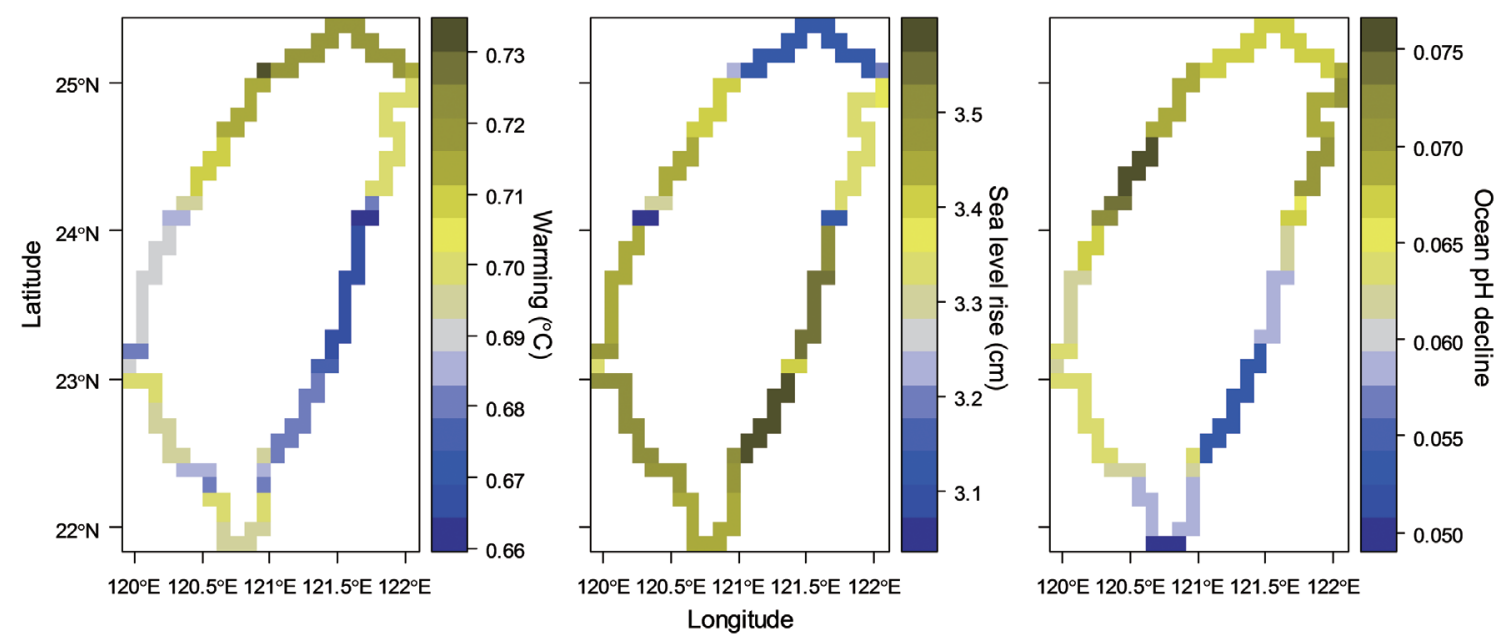

Fig. 3. Projected changes in sea level, sea temperature and ocean acidity by 2020 - 2039 (relative to 1980 - 1999) based on the average of 16 general circulation model-emissions scenarios.

Table 3. Vulnerability (V), the product of hazard and exposure (HE), and risk assessments for coastal ecosystems to climate change under observed (1980 - 1999; Base) and projected (2020 - 2039; Future) conditions. Each spatial patch (see Fig. 2) belonging to the same ecosystem has the same value at risk because scores for each hazard are the same all around Taiwan.

\begin{tabular}{l|r|r|r|r:r|r}
\hline \multirow{2}{*}{\multicolumn{1}{c|}{ Ecosystem }} & \multirow{2}{*}{ V } & \multicolumn{2}{|c|}{ Base } & \multicolumn{2}{c|}{ Future } & \multirow{2}{*}{ Risk difference } \\
\cline { 3 - 6 } & & HE & Risk & HE & Risk & \\
\hline Rocky shore & 2.4 & 2.0 & 4.9 & 3.7 & 9.0 & 4.1 \\
Sandy shore & 3.1 & 1.3 & 4.1 & 2.7 & 8.2 & 4.1 \\
Estuary/coastal lagoon & 2.9 & 2.7 & 7.6 & 5.0 & 14.3 & 6.7 \\
Coral reefs & 2.8 & 4.0 & 11.3 & 9.0 & 25.5 & 14.2 \\
Mangroves & 3.1 & 2.7 & 8.3 & 4.7 & 14.5 & 6.2 \\
Seagrass beds & 3.1 & 3.3 & 10.4 & 6.3 & 19.8 & 9.4 \\
Algal reefs & 3.8 & 3.3 & 12.8 & 7.7 & 29.4 & 16.6 \\
\hline
\end{tabular}


ecosystem has high sensitivity and low recovery potential, and it is impacted by a range of socioeconomic factors, including, recreational activities, fishing, and intense coastal land use.

\section{DISCUSSION}

To understand the possible climate change effects on the Taiwan coastal ecosystems, it is necessary and essential to develop a robust framework for assessing the risks associated with climate change. This study provides just such a framework and the associated criteria needed to determine the future risks from climate change to coastal ecosystems. This could boost future efforts to manage these ecosystems and develop strategies to avoid, mitigate, and adapt to the effects of climate change in Taiwan. We include a wide range of factors in the framework, including ecosystem responses, socioeconomic effects, and multiple climatic hazards. The comprehensive nature of our framework could limit its use if insufficient data is available. In Taiwan, we have inadequate information and ecological knowledge to meet the framework requirements and, so, we cannot accurately assess future risk. However, the overall pattern, but not the details in the assessment can provide insights into the fate of these coastal ecosystems. Our results indicate that, by 2039, increasing ocean temperature and acidification, will severely impact coastal ecosystems and that the sea level rise effects will be less severe.

Coastal ecosystems are not subject to just one climate hazard, but to multiple climatic hazards, such as sea level rise, increasing temperature, and ocean acidification. These hazards affect physicochemical factors, which then impact coastal ecosystems and their biological components (Dijkstra et al. 2011). Moreover, when it comes to developing management strategies, knowing which hazard is most significant for coastal ecosystems in Taiwan is critical. Our and other studies demonstrate how to identify the effects of single and combined climatic hazards (Morzaria-Luna et al. 2014). It is crucial that we develop ways of quantifying the interactive effects of multiple climatic stressors at the community or ecosystem level. Climatic hazard interactions are complex and there is insufficient information to separate the effects of each action based on global studies, much less on those in Taiwan. Climatic hazards, such as sea level rise, increasing ocean temperature, and ocean acidification, can have cumulative and synergistic effects that are usually non-measurable and increase the uncertainty of risk assessments (Morzaria-Luna et al. 2014). For example, there are individual, additive, and interactive effects from fishing, ocean warming, and ocean acidification over time on the southeastern Australian marine ecosystem. These effects vary depending on the ecosystem or community (Griffith et al. 2012).

Different coastal ecosystems, including coral reefs, algal reefs, mangroves, and salt marshes, exhibit different responses to the same climatic hazards, e.g., sea level rise, ocean warming, and ocean acidification. For example, the rising atmospheric concentration of carbon dioxide $\left(\mathrm{CO}_{2}\right)$ is causing higher oceanic uptake of $\mathrm{CO}_{2}$ and ocean acidification, which affects seawater chemistry and could negatively affect calcifying marine organisms (Griffith et al. 2011). Coral and algal reefs appear to be sensitive to ocean acidification and increasing temperature, but these hazards may have little or no impacts on mangroves and salt marshes. Compared to corals, mangroves are better able to resist ocean acidification because of habitat heterogeneity, proximity of different habitat types, hydrographic conditions, and biological effects on seawater chemistry generate chemical conditions that buffer against ocean acidification (Yates et al. 2014). This variation in response makes comparing the risk of climate change hazards to different coastal ecosystems a major challenge and few studies focus on multiple coastal ecosystems. To make the risks to different ecosystems comparable, we used the exposure of different ecosystems to integrate and track changes in their vulnerability within a whole-ecosystem modeling framework that includes the trophic web and energy flow. Our framework is semi-quantized and each ecosystem's exposure determined by expert assessments. To the best of our knowledge, this is the first study that integrates trophic web and energy flow into the framework for assessing ecological risk. This framework could be useful in urgent situations when quantified exposures based on experiments, surveys, or models are not available.

One of the most important future climate change effects could be the decreased viability of individual species (Nagelkerken and Munday 2016). Climate change will alter the environment and habitats, and could affect the physiology and behavior of all individuals of given species (Kendall et al. 2016). Species can develop resistance and resilience to climate change through evolutionary adaptation (Chirgwin et al. 2015). In addition, species may move as the locations of suitable environments change (Brown et al. 2016). For example, if the rate of sea level and temperature rise are slow enough, mangroves can adapt by moving inland and to areas that used to be too cold (Yáñez-Espinosa and Flores 2011). Direct human impacts, such as overfishing and water pollution, likely decrease the adaptive capacity of most species (Rogers et al. 2015). Therefore, it is important to study evolutionary adaptation because it can help mitigate the effects of climate change and inform human adaptation strategies to decrease the socioeconomic costs. Management or mitigation strategies that limit climate hazards below a reasonable level could increase the chances for species in coastal ecosystems to adapt evolutionarily to climate change (Gattuso et al. 2015). In addition, to limit changes in the structure of communities, effective management must limit the increase and range expansion of tolerant and 
invasive species (Przeslawski et al. 2008).

Integrating socioeconomic factors into risk assessments of climatic hazards is one of the major challenges. Understanding the ecological impacts of future climatic hazards and assessing the socioeconomic costs of adaptation strategies on coastal ecosystems is essential (Wolff et al. 2015). Adaptation planning must consider socioeconomic dynamics and the tradeoffs between ecosystems and socioeconomics. For example, in Papua New Guinea, adaptation planning for coral reef fisheries could be improved by integrating social-ecological vulnerability assessments with climate forecasts (Maina et al. 2016). Our methodology includes resource exploitation factors that affect the adaptive capacity of ecosystems. As resource exploitation increases, an ecosystem's adaptive capacity decreases. For example, a study assessing the potential impact of fishing and acidification demonstrated that areas subject to intensive fishing were at greatest risk and most susceptible to the effects of acidification (Griffith et al. 2011). The same ecosystems in different areas and different ecosystems in the same area can differ considerably in their adaptive capacity and in their vulnerability to predicted climatic hazards due to future climate change. Collecting and integrating social information with climate forecasts and ecosystem modeling will better address the impacts of climate-mediated hazards. When designing adaptation strategies, enhanced adaptive capacity will decrease risk but impact socioeconomics. Our framework can help policy makers find a balance between ecological adaptation and socioeconomic development.

Although our study focuses on Taiwan, our comprehensive framework considers both ecosystem responses and socioeconomic factors and is the one of several studies worldwide working to understand the effects of climate change and assist in the development of effective management and adaptation strategies. However, inadequate ecological information limits the effectiveness and power of this framework. The framework structure and the criteria for risk estimation are based on a few, important ecological studies and general, global concepts and information. The lack of information specific to Taiwan may decrease the accuracy of our predictions and constrain the timely development of effective adaptation strategies for Taiwan. There is a shortage of information about ecosystem vulnerability. We need comprehensive studies on species ecology in the coastal ecosystems of Taiwan and their interactions with biotic and abiotic factors. It is essential to have information that is more detailed and more comprehensive and have the participation of more scientists and policy-makers.

Our ecosystem vulnerability framework is based on energy flow and food web structure. Ideally, ecosystem vulnerability should be hazard-specific because different habitat conditions and community structure determine ecosystem features. For example, coral reefs are sensitive to water temperature, and ocean warming could result in coral bleaching and directly affect other biotic assemblages (Keshavmurthy et al. 2014). Therefore, future efforts to refine this framework should address energy flow dynamics and food web structure in response to hazards. This will facilitate detailed risk assessments for a broad range of ecosystems and climatic hazards, and improve the development of effective strategies that protect ecosystems and minimize socioeconomic impacts.

Acknowledgements We thank the two Anonymous Referees who commented on this manuscript. The Ministry of Science and Technology, Taiwan supported this study with grants (101-2625-M-005-004).

\section{REFERENCES}

Anthony, K. R. N., P. A. Marshall, A. Abdulla, R. Beeden, C. Bergh, R. Black, C. M. Eakin, E. T. Game, M. Gooch, N. A. J. Graham, A. Green, S. F. Heron, R. van Hooidonk, C. Knowland, S. Mangubhai, N. Marshall, J. A. Maynard, P. McGinnity, E. McLeod, P. J. Mumby, M. Nyström, D. Obura, J. Oliver, H. P. Possingham, R. L. Pressey, G. P. Rowlands, J. Tamelander, D. Wachenfeld, and S. Wear, 2015: Operationalizing resilience for adaptive coral reef management under global environmental change. Global Change Biol., 21, 48-61, doi: $10.1111 / \mathrm{gcb} .12700$. [Link]

Ateweberhan, M., D. A. Feary, S. Keshavmurthy, A. Chen, M. H. Schleyer, and C. R. C. Sheppard, 2013: Climate change impacts on coral reefs: Synergies with local effects, possibilities for acclimation, and management implications. Mar. Pollut. Bull., 74, 526-539, doi: 10.1016/j.marpolbul.2013.06.011. [Link]

Barbier, E. B., S. D. Hacker, C. Kennedy, E. W. Koch, A. C. Stier, and B. R. Silliman, 2011: The value of estuarine and coastal ecosystem services. Ecol.monogr., 81, 169-193, doi: 10.1890/10-1510.1. [Link]

Brown, C. J., M. I. O’Connor, E. S. Poloczanska, D. S. Schoeman, L. B. Buckley, M. T. Burrows, C. M. Duarte, B. S. Halpern, J. M. Pandolfi, C. Parmesan, and A. J. Richardson, 2016: Ecological and methodological drivers of species' distribution and phenology responses to climate change. Global Change Biol., 22, 1548-1560, doi: 10.1111/gcb.13184. [Link]

Chen, T. S. and H. J. Lin, 2011: Application of a landscape development intensity index for assessing wetlands in Taiwan. Wetlands, 31, 745-756, doi: 10.1007/s13157011-0191-6. [Link]

Chin, A., P. M. Kyne, T. I. Walker, and R. B. Mcauley, 2010: An integrated risk assessment for climate change: Analysing the vulnerability of sharks and rays on Australia's Great Barrier Reef. Global Change Biol., 16, 1936-1953, doi: 10.1111/j.1365-2486.2009.02128.x. [Link] 
Chirgwin, E., K. Monro, C. M. Sgro, and D. J. Marshall, 2015: Revealing hidden evolutionary capacity to cope with global change. Global Change Biol., 21, 33563366, doi: $10.1111 / \mathrm{gcb} .12929$. [Link]

Christensen, V., C. J. Walters, D. Pauly, and R. Forrest, 2008: Ecopath with Ecosim Version 6: User Guide, Fisheries Centre, University of British Columbia, Vancouver, Canada, 235 pp.

Czúcz, B., A. Csecserits, Z. Botta-Dukát, G. Kröel-Dulay, R. Szabó, F. Horváth, and Z. Molnár, 2011: An indicator framework for the climatic adaptive capacity of natural ecosystems. J. Veg. Sci., 22, 711-725, doi: 10.1111/j.1654-1103.2011.01251.x. [Link]

Danielsen, F., M. K. Sorensen, M. F. Olwig, V. Selvam, F. Parish, N. D. Burgess, T. Hiraishi, V. M. Karunagaran, M. S. Rasmussen, L. B. Hansen, A. Quarto, and N. Suryadiputra, 2005: The Asian tsunami: A protective role for coastal vegetation. Science, 310, 643-643, doi: 10.1126/science.1118387. [Link]

Dijkstra, J. A., E. L. Westerman, and L. G. Harris, 2011: The effects of climate change on species composition, succession and phenology: A case study. Global Change Biol., 17, 2360-2369, doi: 10.1111/j.13652486.2010.02371.x. [Link]

Gattuso, J. P., A. Magnan, R. Bille, W. W. L. Cheung, E. L. Howes, F. Joos, D. Allemand, L. Bopp, S. R. Cooley, C. M. Eakin, O. Hoegh-Guldberg, R. P. Kelly, H. O. Pörtner, A. D. Rogers, J. M. Baxter, D. Laffoley, D. Osborn, A. Rankovic, J. Rochette, U. R. Sumaila, S. Treyer, and C. Turley, 2015: Contrasting futures for ocean and society from different anthropogenic $\mathrm{CO}_{2}$ emissions scenarios. Science, 349, doi: 10.1126/science.aac4722. [Link]

Gillanders, B. M., T. S. Elsdon, I. A. Halliday, G. P. Jenkins, J. B. Robins, and F. J. Valesini, 2011: Potential effects of climate change on Australian estuaries and fish utilising estuaries: A review. Mar. Freshw. Res., 62, 1115-1131, doi: 10.1071/Mf1 1047. [Link]

Griffith, G. P., E. A. Fulton, and A. J. Richardson, 2011: Effects of fishing and acidification-related benthic mortality on the southeast Australian marine ecosystem. Global Change Biol., 17, 3058-3074, doi: 10.1111/j.1365-2486.2011.02453.x. [Link]

Griffith, G. P., E. A. Fulton, R. Gorton, and A. J. Richardson, 2012: Predicting interactions among fishing, ocean warming, and ocean acidification in a marine system with whole-ecosystem models. Conserv. Biol., 26, 11451152, doi: 10.1111/j.1523-1739.2012.01937.x. [Link]

Halpern, B. S., S. Walbridge, K. A. Selkoe, C. V. Kappel, F. Micheli, C. D’Agrosa, J. F. Bruno, K. S. Casey, C. Ebert, H. E. Fox, R. Fujita, D. Heinemann, H. S. Lenihan, E. M. P. Madin, M. T. Perry, E. R. Selig, M. Spalding, R. Steneck, and R. Watson, 2008: A global map of human impact on marine ecosystems. Science, $\mathbf{3 1 9}$,
948-952, doi: 10.1126/science.1149345. [Link]

Hinkel, J., R. J. Nicholls, A. T. Vafeidis, R. S. J. Tol, and T. Avagianou, 2010: Assessing risk of and adaptation to sea-level rise in the European Union: An application of DIVA. Mitig. Adapt. Strateg. Glob. Change, 15, 703719, doi: 10.1007/s11027-010-9237-y. [Link]

IPCC, 2013: Climate Change 2013: The Physical Science Basis, Contribution of Working Group I to the Fifth Assessment Report of the Intergovernmental Panel on Climate Change, Cambridge University Press, Cambridge, United Kingdom and New York, NY, USA, 1535 pp, doi: 10.1017/CBO9781107415324. [Link]

IPCC, 2014: Climate Change 2014: Impacts, Adaptation, and Vulnerability, Contribution of Working Group II to the Fifth Assessment Report of the Intergovernmental Panel on Climate Change, Cambridge University Press, Cambridge, United Kingdom and New York, NY, USA.

Kendall, M. S., M. Poti, and K. B. Karnauskas, 2016: Climate change and larval transport in the ocean: Fractional effects from physical and physiological factors. Global Change Biol., 22, 1532-1547, doi: 10.1111/ gcb.13159. [Link]

Keshavmurthy, S., P. J. Meng, J. T. Wang, C. Y. Kuo, S. Y. Yang, C. M. Hsu, C.H. Gan, C. F. Dai, and C. A. Chen, 2014: Can resistant coral-Symbiodinium associations enable coral communities to survive climate change? A study of a site exposed to long-term hot water input. PeerJ, 2, e327, doi: 10.7717/peerj.327. [Link]

Lee, C. L., Y. H. Huang, C. Y. Chung, S. C. Hsiao, and H. J. Lin, 2015: Herbivory in multi-species, tropical seagrass beds. Mar. Ecol. Prog. Ser., 525, 65-80, doi: 10.3354/meps11220. [Link]

Li, S. S., X. W. Meng, Z. M. Ge, and L. Q. Zhang, 2015: Vulnerability assessment of the coastal mangrove ecosystems in Guangxi, China, to sea-level rise. Reg. Environ. Change, 15, 265-275, doi: 10.1007/s10113-0140639-3. [Link]

Lin, H. J., K. T. Shao, S. R. Kuo, H. L. Hsieh, S. L. Wong, I. M. Chen, W. T. Lo, and J. J. Hung, 1999: A trophic model of a sandy barrier lagoon at Chiku in southwestern Taiwan. Estuar. Coast. Shelf Sci., 48, 575-588, doi: 10.1006/ecss.1998.0457. [Link]

Lin, H. J., K. T. Shao, W. L. Chiou, C. J. W. Maa, H. L. Hsieh, W. L. Wu, L. L. Severinghaus, and Y. T. Wang, 2003: Biotic communities of freshwater marshes and mangroves in relation to saltwater incursions: Implications for wetland regulation. Biodivers. Conserv., 12, 647-665, doi: 10.1023/A:1022405213732. [Link]

Lin, H. J., K. T. Shao, J. S. Hwang, W. T. Lo, I. J. Cheng, and L. H. Lee, 2004: A trophic model for Kuosheng Bay in northern Taiwan. J. Mar. Sci. Technol., 12, 424-432.

Lin, H. J., X. X. Dai, K. T. Shao, H. M. Su, W. T. Lo, H. L. Hsieh, L. S. Fang, and J. J. Hung, 2006: Trophic 
structure and functioning in a eutrophic and poorly flushed lagoon in southwestern Taiwan. Mar. Environ. Res., 62, 61-82, doi: 10.1016/j.marenvres.2006.03.003. [Link]

Lin, H. J., H. F. Hsu, W. S. Liao, C. L. Lee, P. J. Liu, and S. M. Lin, 2013: Biodiversity of the algal reefs in Taoyuan. J. Wetland, 2, 1-24.

Liu, P. J., K. T. Shao, R. Q. Jan, T. Y. Fan, S. L. Wong, J. S. Hwang, J. P. Chen, C. C. Chen, and H. J. Lin, 2009: A trophic model of fringing coral reefs in Nanwan Bay, southern Taiwan suggests overfishing. Mar. Environ. Res., 68, 106-117, doi: 10.1016/j.marenvres.2009.04.009. [Link]

Maina, J., J. Kithiia, J. Cinner, E. Neale, S. Noble, D. Charles, and J. E. M. Watson, 2016: Integrating socialecological vulnerability assessments with climate forecasts to improve local climate adaptation planning for coral reef fisheries in Papua New Guinea. Reg. Environ. Change, 16, 881-891, doi: 10.1007/s10113-0150807-0. [Link]

McClanahan, T. R., S. D. Donner, J. A. Maynard, M. A. MacNeil, N. A. J. Graham, J. Maina, A. C. Baker, J. B. Alemu I., M. Beger, S. J. Campbell, E. S. Darling, C. M. Eakin, S. F. Heron, S. D. Jupiter, C. J. Lundquist, E. McLeod, P. J. Mumby, M. J. Paddack, E. R. Selig, and R. van Woesik, 2012: Prioritizing key resilience indicators to support coral reef management in a changing climate. PLoS One, 7, e42884, doi: 10.1371/journal. pone.0042884. [Link]

Morzaria-Luna, H., P. Turk-Boyer, A. Rosemartin, and V. E. Camacho-Ibar, 2014: Vulnerability to climate change of hypersaline salt marshes in the Northern Gulf of California. Ocean. Coast. Manage., 93, 37-50, doi: 10.1016/j.ocecoaman.2014.03.004. [Link]

Nagelkerken, I. and P. L. Munday, 2016: Animal behaviour shapes the ecological effects of ocean acidification and warming: Moving from individual to community-level responses. Global Change Biol., 22, 974-989, doi: 10.1111/gcb.13167. [Link]

Odum, E. P., 1969: The strategy of ecosystem development. Science, 164, 262-270, doi: 10.1126/science.164.3877.262. [Link]

Orr, J. C., V. J. Fabry, O. Aumont, L. Bopp, S. C. Doney, R. A. Feely, A. Gnanadesikan, N. Gruber, A. Ishida, F. Joos, R. M. Key, K. Lindsay, E. Maier-Reimer, R. Matear, P. Monfray, A. Mouchet, R. G. Najjar, G. K. Plattner, K. B. Rodgers, C. L. Sabine, J. L. Sarmiento, R. Schlitzer, R. D. Slater, I. J. Totterdell, M. F. Weirig, Y. Yamanaka, and A. Yool, 2005: Anthropogenic ocean acidification over the twenty-first century and its impact on calcifying organisms. Nature, 437, 681686, doi: 10.1038/nature04095. [Link]

Pan, C. W., M. H. Chen, L. S. Chou, and H. J. Lin, 2016: The trophic significance of the Indo-Pacific humpback dol- phin, Sousa chinensis, in Western Taiwan. PLoS ONE, 11, e0165283, doi: 10.1371/journal.pone.0165283. [Link]

Przeslawski, R., S. Ahyong, M. Byrne, G. WÖRheide, and P. A. T. Hutchings, 2008: Beyond corals and fish: The effects of climate change on noncoral benthic invertebrates of tropical reefs. Global Change Biol., 14, 27732795, doi: 10.1111/j.1365-2486.2008.01693.x. [Link]

Rogers, A., A. R. Harborne, C. J. Brown, Y. M. Bozec, C. Castro, I. Chollett, K. Hock, C. A. Knowland, A. Marshell, J. C. Ortiz, T. Razak, G. Roff, J. Samper-Villarreal, M. I. Saunders, N. H. Wolff, and P. J. Mumby, 2015: Anticipative management for coral reef ecosystem services in the 21st century. Global Change Biol., 21, 504-514, doi: 10.1111/gcb.12725. [Link]

Simas, T., J. P. Nunes, and J. G. Ferreira, 2001: Effects of global climate change on coastal salt marshes. Ecol. Model.,139,1-15, doi: 10.1016/S0304-3800(01)002265. [Link]

Spalding, M. D., S. Ruffo, C. Lacambra, I. Meliane, L. Z. Hale, C. C. Shepard, and M. W. Beck, 2014: The role of ecosystems in coastal protection: Adapting to climate change and coastal hazards. Ocean. Coast. Manage., 90, 50-57, doi: 10.1016/j.ocecoaman.2013.09.007. [Link]

Torresan, S., A. Critto, J. Rizzi, and A. Marcomini, 2012: Assessment of coastal vulnerability to climate change hazards at the regional scale: The case study of the North Adriatic Sea. Nat. Hazards Earth Syst. Sci., 12, 2347-2368, doi: 10.5194/nhess-12-2347-2012. [Link]

Ulanowicz, R. E., 2001: Information theory in ecology. Comput. Chem., 25, 393-399, doi: 10.1016/S00978485(01)00073-0. [Link]

Wolff, N. H., S. D. Donner, L. Cao, R. Iglesias-Prieto, P. F. Sale, and P. J. Mumby, 2015: Global inequities between polluters and the polluted: Climate change impacts on coral reefs. Global Change Biol., 21, 39823994, doi: 10.1111/gcb.13015. [Link]

Worm, B., E. B. Barbier, N. Beaumont, J. E. Duffy, C. Folke, B. S. Halpern, J. B. C. Jackson, H. K. Lotze, F. Micheli, S. R. Palumbi, E. Sala, K. A. Selkoe, J. J. Stachowicz, and R. Watson, 2006: Impacts of biodiversity loss on ocean ecosystem services. Science, 314, 787-790, doi: 10.1126/science.1132294. [Link]

Yáñez-Espinosa, L. and J. Flores, 2011: A review of sealevel rise effect on mangrove forest species: Anatomical and morphological modifications. In: Casalegno, S. (Ed.), Global Warming Impacts - Case Studies on the Economy, Human Health, and on Urban and Natural Environments, InTech, Croatia, 253-276, doi: 10.5772/1935. [Link]

Yates, K. K., C. S. Rogers, J. J. Herlan, G. R. Brooks, N. A. Smiley, and R. A. Larson, 2014: Diverse coral communities in mangrove habitats suggest a novel refuge from climate change. Biogeosciences, 11, 4321-4337, 
doi: 10.5194/bg-11-4321-2014. [Link]

Ye, N. T., 2007: Studies on the fish community structure, feeding guilds and trophic model in Yenliao Bay. Master Thesis, Institute of Marine Biology, National Taiwan Ocean University, Keelung City, Taiwan, 82 pp.
Yemshanov, D., F. H. Koch, M. Ducey, and K. Koehler, 2013: Mapping ecological risks with a portfolio-based technique: Incorporating uncertainty and decisionmaking preferences. Divers. Distrib., 19, 567-579, doi: 10.1111/ddi.12061. [Link] 